\title{
SOROPREVALÊNCIA DE TOXOPLASMOSE HUMANA NA CIDADE DE TERESINA, NO PERÍODO DE 2010 A 2014
}

Alexandra Maria dos Santos Carvalho

Graduada em Biomedicina, pela Universidade Federal do Piauí (UFPI), Campus Universitário Ministro Reis Velloso, Brasil.

E-mail: alexandrasantos22@hotmail.com

\section{Fabiana Andreína da Silva Sátiro}

Discente de Biomedicina, pela Universidade Federal do Piauí (UFPI), Campus Universitário Ministro Reis Velloso, Brasil.

\section{Rhuana Marianne da Paz Oliveira}

Graduada em Biomedicina, pela Universidade Federal do Piauí (UFPI), Campus Universitário Ministro Reis Velloso, Brasil.

\section{Cláudio Ângelo Ventura}

Doutorado em Biologia Funcional e Molecular Universidade Estadual de Campinas (UNICAMP), Brasil; Docente na Universidade Federal do Piauí, Campus Ministro Reis Velloso, Brasil.
RESUMO: A toxoplasmose é uma zoonose cosmopolita causada pelo Toxoplasma gondii. A enfermidade constitui um importante problema de saúde pública em todo o mundo, especialmente na sua forma congênita, onde o risco de comprometimento fetal e sequelas são iminentes. Objetivou-se estabelecer o perfil epidemiológico da toxoplasmose na cidade de Teresina (PI), por meio da caracterização de sua prevalência em humanos, durante o período de 2010 a 2014. Foi realizado um estudo descritivo e retrospectivo de caráter quantitativo. Observou-se que 69\% dos indivíduos do sexo feminino apresentam soropositividade em relação a anticorpos IgG contra toxoplasmose, enquanto que $67 \%$ dos indivíduos do sexo masculino apresentam soropositividade. De acordo com as análises estatísticas, a prevalência de toxoplasmose na cidade de Teresina é de $89,4 \%$ em relação a anticorpos $\operatorname{IgG}$, e 4,3\% para anticorpos IgM. Fica evidente que estudos adicionais são necessários antes da completa compreensão da prevalência de toxoplasmose em Teresina. Diante do exposto, percebese a importância da caracterização epidemiológica da toxoplasmose, visto que o aumento na incidência de AIDS no Estado do Piauí vem aumentando gradativamente. Conclui-se que são necessários maiores estudos sobre incidência e prevalência no Estado do Piauí, bem como o estudo sobre incidências das variações clínicas da toxoplasmose.

PALAVRAS-CHAVE: Doenças Parasitárias; Prevalência; Toxoplasma; Toxoplasmose.

\section{SERUM PREVALENCE OF HUMAN TOXOPLASMOSIS IN TERESINA, BRAZIL, BET WEEN 2010 AND 2014}

ABSTRACT: Toxoplasmosis is a world-wide zoonosis caused by Toxoplasma gondii. It is an important public health problem especially in its congenital form where risk to the fetus and its sequences are imminent. The epidemiological profile of toxoplasmosis in Teresina PI Brazil is described by characterizing its prevalence in humans between 2010 and 2014. The descriptive and retrospective analysis showed that $69 \%$ of females were serum positive with regard to antibodies IgG against toxoplasmosis, whereas $67 \%$ of males were serum positive. Statistical analyses revealed that the prevalence of toxoplasmosis in Teresina reached $89.4 \%$ with regard to antibodies IgG and $4.3 \%$ for antibodies IgM. Further studies are required to understand fully the prevalence of toxoplasmosis in the city. The epidemiological characterization of toxoplasmosis is highly relevant due to a gradual increase in AIDS rates in the state of Piauí. Further studies on its occurrence and prevalence in the state of Piauí are required, coupled to studies on the clinical variations of toxoplasmosis.

KEY WORDS: Toxoplasmosis, Toxoplasma, Prevalence, Diseases by Parasites. 


\section{INTRODUÇãOO}

A toxoplasmose é uma zoonose cosmopolita causada pelo Toxoplasma gondii, protozoário intracelular obrigatório e parasita de humanos, pássaros, roedores, outros animais homeotérmicos e felídeos, sendo este último o hospedeiro definitivo (AMENDOEIRA; CAMILLO-COURA, 2010). Animais ectotérmicos, ou seja, de sangue frio, como peixes e répteis não são infectados pelo parasita. Tal enfermidade constitui um importante problema de saúde pública em todo o mundo, especialmente na sua forma congênita, onde o risco de comprometimento fetal e sequelas são iminentes (MEDEIROS, 2010; BECK et al., 2010).

As condições clínicas manifestadas pela presença do protozoário T. gondii no organismo humano, geralmente, são assintomáticas, mas, nos casos agudos, pode causar febre, linfodenopatia, coriorretinite, linfocitose e dores musculares que persistem durante dias ou semanas. O protozoário acomete também órgãos como o pulmão, o coração, o fígado e o cérebro (EDUARDO et al., 2013).

A gravidade da infecção causada pelo protozoário varia conforme a condição imunológica, humoral e celular do indivíduo, indo de sintomas muito brandos a ausentes. As formas clínicas mais graves geralmente ocorrem em indivíduos imunocomprometidos e em gestantes. Indivíduos portadores de AIDS, pacientes em tratamentos oncológicos, transplantados ou portadores de imunodeficiências podem elevar os índices de morbidade e mortalidade. Nestes casos, a doença se manifesta por quadros neurológicos, podendo ser fatal em casos de atraso no tratamento (VAZ et al., 2011).

A transmissão transplacentária ocorre por infecção primária ao longo dos três trimestres da gestação. A gravidade das lesões está relacionada à fase gestacional e as consequências podem ser maiores quanto mais jovens forem os fetos (AMENDOEIRA; CAMILLO-COURA, 2010).

O T. gondii expressa antígenos de superfície (SAG) os quais são codificados por genes de cópias únicas e que têm importante papel nos mecanismos imunes, patogênicos e na invasão celular (MEDEIROS, 2010; FERREIRA, 2012). A resposta imune do hospedeiro à toxoplasmose é complexa e a gravidade da doença está estritamente relacionada à capacidade do hospedeiro responder imunologicamente à infecção.

A prevenção da toxoplasmose torna-se mais importante em imunocomprometidos e mulheres grávidas devido ao risco de transmissão transplacentária, visto que, em tais condições, a doença pode ser fatal. A melhor forma para prevenir a toxoplasmose é utilizar medidas primárias de prevenção, que consistem em evitar o contato com as fezes de gatos, preparar adequadamente as carnes, evitar o consumo de carnes cruas ou mal passadas, mesmo daquelas que tenham sido congeladas previamente. Lavar cuidadosamente as mãos com sabão depois de manusear carne crua durante seu preparo e limpar diariamente os ambientes domésticos contaminados com fezes de gatos com o auxílio de luvas, para evitar o contato com as fezes (NADIR JÚNIOR et al., 2012; BATISTA, 2013; COSTA, 2013).

As estratégias de prevenção da toxoplasmose congênita compreendem, entre outras, práticas educativas (profilaxia primária) que visam reduzir a exposição às fontes de infecção, e a triagem sorológica pré-natal para identificar e tratar a infecção aguda durante a gestação (BRANCO; ARAÚJO; CASTILHO-PELLOSO, 2005).

Estudos relacionados à epidemiologia da toxoplasmose são escassos no Estado do Piauí. Desta forma, não se sabe qual a real prevalência e incidência desta patologia. A carência de campanhas de saúde pública relacionadas à toxoplasmose constitui um fator favorável para a alta prevalência mundial. O Centro de Controle e prevenção de doenças (CDC - Centers for Disease Control and Prevention) estima que, nos Estados Unidos, 22,5\% da população de 12 anos ou mais foram infectados com Toxoplasma gondii. No Brasil, as frequências são distintas, variando de $50,5 \%$ a $82 \%$ em diversos segmentos da população adulta. A prevalência de anticorpos IgG na população geral varia de $54 \%$ no Centro-Oeste a $75 \%$ no Norte (FIGUEIRO-FILHO et al., 2005; CASTILHO-PELLOSO, 2005).

Levando-se em consideração a importância da toxoplasmose no período gestacional e a escassez de publicações no Estado do Piauí, é de grande relevância a aplicação deste estudo. Pois o mesmo pode auxiliar no planejamento de ações profiláticas e campanhas 
para dispersão do conhecimento sobre a mesma. Dessa forma, objetivou-se estabelecer o perfil epidemiológico da toxoplasmose na cidade de Teresina (PI), por meio da caracterização de sua prevalência em humanos, durante o período de 2010 a 2014.

\section{METODOLOGIA}

A pesquisa foi realizada no polo de saúde do município de Teresina (PI). A cidade localiza-se no CentroNorte piauiense, a $366 \mathrm{~km}$ do litoral. O referido município possui uma área de aproximadamente $1.391,981 \mathrm{~km}^{2} \mathrm{e}$ uma população total estimada em 840.600 habitantes (IBGE, 2014), sendo que está limítrofe a cidade de Timon, Maranhão.

Fora realizado um estudo descritivo e retrospectivo de caráter quantitativo. A população estudada foi composta por indivíduos do sexo masculino e feminino, independente da idade, raça ou cor, estado geral de saúde e classe social, atendidos pelo Laboratório Central de Saúde Pública Doutor Costa Alvarenga (LACEN), Maternidade Dona Evangelina Rosa, Hospital Infantil Lucídio Portela, Instituto de Doenças Tropicais Natan Portella, Centro de Saúde Avelino Lopes, Hospital de Urgência de Teresina Professor Zenon Rocha, Hospital Getúlio Vargas e no Laboratório Raul Bacelar. Excluiu-se os indivíduos não residentes em Teresina.

$O$ referido instrumento de coleta de dados abrangeu informações de pacientes atendidos por variáveis como nome, teste e o método utilizado, município de residência e resultado dos testes.

Após o recebimento dos dados, estes foram inclusos em planilhas de estudo construídas para análise por meio do programa estatístico BioEstat ${ }^{\circledR}$ 5.0. Posteriormente foram construídas figuras demonstrativas, que serviram de base para a apresentação dos resultados e sua discussão à luz da literatura especializada. A partir dos dados obtidos, calculou-se a taxa de prevalência de toxoplasmose humana (TH) por 100.000 habitantes em Teresina (PI) utilizando-se a seguinte fórmula:

PREVALÊNCIA $=\underline{\left(\mathrm{N}^{0} \text { de casos TH diagnosticados }\right)} \times 100.000$ ( $\mathrm{N}^{\mathrm{O}}$ da população total)
Este estudo foi aprovado pelo Comitê de Ética em Pesquisa, sob o número CAAE 44759515.9.0000.5214.

\section{RESULTADOS E DISCUSSÂO}

Os dados coletados durante o estudo corresponderam ao período entre julho de 2010 e abril de 2014. Obteve-se 3.637 ocorrências, tanto do sexo masculino quanto feminino registradas no Laboratório Central de Saúde Pública Doutor Costa Alvarenga (LACEN).

Estas solicitações compreendem testes imunológicos do tipo Imunoensaio Enzimático de Micropartículas, Enzimaimunoensaio (ELISA) e Imunoensaio por Quimiluminescência. Todos estes buscam a presença de anticorpos anti-T. gondii do tipo IgG ou IgM.

O LACEN, além de realizar os testes sorológicos para toxoplasmose armazena os resultados dos testes realizados pelas seguintes instituições públicas: Maternidade Evangelina Rosa, Hospital Infantil Lucídio Portela, Instituto de Doenças Tropicais Natan Portella, Centro de Saúde Avelino Lopes, Hospital de Urgência de Teresina Professor Zenon Rocha, Hospital Getúlio Vargas e Laboratório Raul Bacelar. Desta forma a planilha contendo os resultados dos testes compreende não somente as análises feitas no LACEN, mas em toda a rede pública de saúde da cidade de Teresina.

Considerando os critérios de avaliação, houve a necessidade de excluir 918 registros dos dados obtidos, pois correspondiam a casos alóctones (oriundos de outras cidades do Estado do Piauí e de outros Estados como Maranhão e Ceará). Desta forma, os números totais de registros avaliados nesta pesquisa são de 2.719 solicitações para pesquisa de anticorpos tanto IgM quanto IgG anti-T. gondii.

Aproximadamente $95 \% \quad(\mathrm{n}=1.038)$ das solicitações para busca de anticorpos anti-T. gondii do tipo IgG foram do sexo feminino e apenas 5\% ( $\mathrm{n}=$ 55) corresponderam ao sexo masculino. Das sorologias realizadas para a busca de anticorpos anti-T. gondii do tipo IgM, $13 \%(\mathrm{n}=217)$ corresponderam a indivíduos do sexo masculino e $87 \%(\mathrm{n}=1.412)$ a indivíduos do 
sexo feminino. Na Figura 1 encontram-se relacionadas as porcentagens dos testes realizados pela rede pública de saúde da cidade de Teresina, para busca de anticorpos do tipo IgG e IgM, considerando os critérios de avaliação previamente estabelecidos nesta pesquisa.

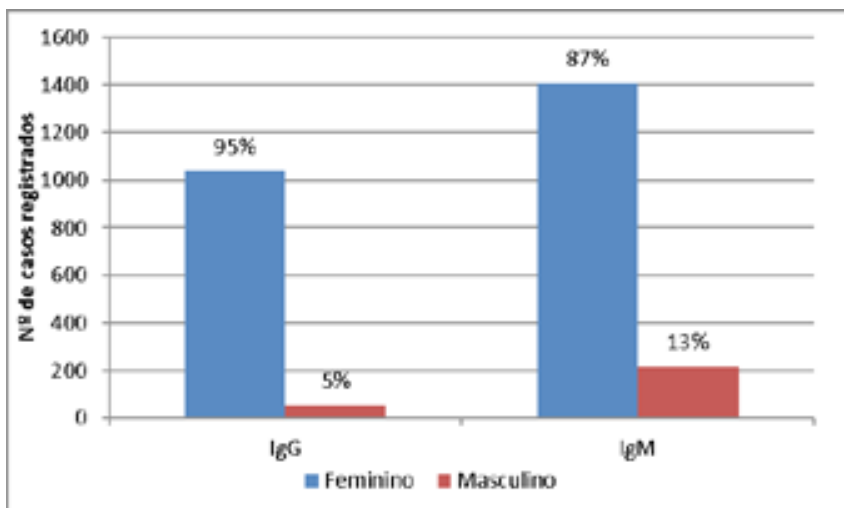

Figura 1. Porcentagem dos casos diagnosticados para anticorpos anti-toxoplasma do tipo IgG e IgM quanto ao sexo.

É notória a discrepância de solicitações entre os sexos, ficando evidente que a toxoplasmose é uma doença negligenciada no sexo masculino e prioritário no sexo feminino. Esquece-se que a toxoplasmose apresenta outras formas clínicas além da toxoplasmose congênita. A infecção causada pelo $T$. gondii apresenta sintomas brandos a severos, o estado imunológico e a faixa etária do paciente determinarão a evolução clínica da infecção pelo protozoário.

A maioria das sorologias para toxoplasmose é requerida no acompanhamento pré-natal e nos neonatos, pois as grávidas sem evidências de infecção, ou seja, mulheres que não estão infectadas pelo protozoário, têm um risco maior de contrair a primo-infecção durante a gestação. Além de causar o aborto, a transmissão transplacentária deste parasita pode levar ao parto precoce, a infecções neonatais, cegueira ou deficiências neurológicas. Por esta razão as mulheres grávidas são a prioridade nas campanhas de prevenção à toxoplasmose, realizadas pelo Ministério da Saúde. As manifestações da infecção congênita pelo protozoário só expressam-se na adolescência ou na vida adulta.

A preocupação em se identificar gestantes com sorologia negativa tanto IgM quanto IgG para o parasito T. gondii é de suma importância. Segundo Beck et al. (2010), nos inquéritos brasileiros realizados em gestantes com diferentes testes sorológicos demonstrou-se uma alta prevalência da toxoplasmose 55 a $70 \%$ de gestantes soropositivas, o que reflete uma frequência entre 30 a $45 \%$ de gestantes brasileiras soronegativas para a toxoplasmose, culminando assim, em um grande risco de contrair toxoplasmose durante a gestação.

$\mathrm{Na}$ Figura 2 encontram-se listadas as percentagens dos testes sorológicos do tipo $\operatorname{IgG}$ e IgM realizados nas instituições que compõem o sistema público de saúde da cidade de Teresina. Nota-se que 60\% ( $\mathrm{n}=1.093)$ dos testes realizados nas instituições são para pesquisa de anticorpos do tipo IgM, e $40 \%(n=1.626)$ para anticorpos $\operatorname{Ig} G$.

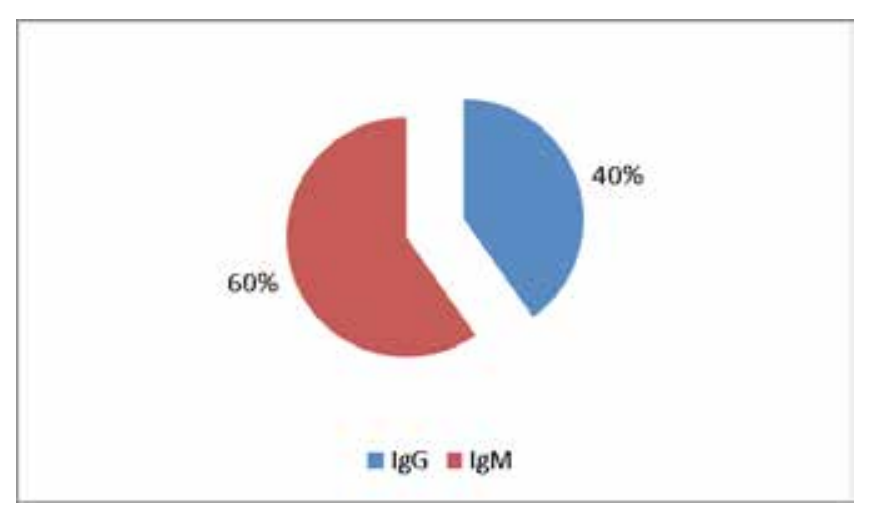

Figura 2. Resultados dos testes para pesquisa de anticorpos antitoxoplasma do tipo IgG e IgM.

Ressalta-se que, apesar da importância e da magnitude da infecção, e das ações de educação em saúde, o conhecimento sobre o tema é restrito à toxoplasmose congênita (KIJLSTRA; JONGERT, 2008 apud COSTA, 2013). As campanhas do Ministério da Saúde são voltadas principalmente para as gestantes prevenindoas a respeito da forma de contágio e prevenção da toxoplasmose congênita. Pouco se fala a respeito das demais apresentações clínicas da toxoplasmose. Na literatura científica os principais achados a respeito da toxoplasmose estão relacionados a gestantes e neonatos, depois surgem os trabalhos relacionados à toxoplasmose em animais de consumo humano e domésticos, em seguida surgem os trabalhos relacionados à toxoplasmose e coinfecção com HIV/AIDS. Poucos são os relatos de casos de toxoplasmose ocular e demais variações clínicas. Fato este que corrobora o negligenciamento das demais apresentações clínicas da toxoplasmose. No Piauí, até o momento não há relatos da prevalência e incidência da 
toxoplasmose em humanos, há apenas poucos relatos relacionados à toxoplasmose em suínos.

Recentemente o Instituto Brasileiro de Geografia e Estatística (IBGE) lançou o documento intitulado como Pesquisa Nacional de Saúde - Acesso e Utilização dos Serviços de Saúde, acidentes e violências (PNS2013) contendo estatísticas atualizadas até o ano de 2013 sobre saúde e diversos fatores demográficos, econômicos, sociais, culturais e ambientais. A PNS 2013 inclui os temas abordados nos Suplementos de Saúde da Pesquisa Nacional por Amostra de Domicílios (PNAD) 1998, 2003 e 2008, e avaliou como um dos critérios de vigilância em saúde a presença de cães e gatos nos domicílios. De acordo com o estudo, no Estado do Piauí, aproximadamente $34,2 \%$ dos domicílios possuem gatos. Isto implica dizer que $34,2 \%$ da população estão sujeitos a contrair toxoplasmose dentro do próprio domicílio. Dos Estados que compõem a região Nordeste, o Piauí é o Estado com o maior número de domicílios com gatos segundo o IBGE.

Como não há vacina contra a toxoplasmose tanto para animais quanto para seres humanos, a melhor forma de prevenir a infecção dos animais domésticos é limitar o acesso dos mesmos a pássaros e roedores, evitar o consumo de carne crua por estes animais e tomar as medidas de prevenção primária. Vale salientar que atualmente o gato não é a principal fonte de infecção, o mesmo é tido como reservatório, somente. A água e os alimentos mal cozidos e mal lavados constituem as fontes de infecção mais citadas na literatura. Ter o gato como animal doméstico não é um pré-requisito para contrair a infecção pelo T. gondii.

Sabe-se que a toxoplasmose manifesta-se severamente em indivíduos submetidos a tratamento de imunossupressão, o que pode acarretar sequelas e até mesmo o óbito dos indivíduos que contraírem ou reagudizarem a toxoplasmose, sendo assim a toxoplasmose não deveria ser tratada como uma exclusividade do acompanhamento pré-natal. De acordo com o Boletim Epidemiológico de 2014 (MINISTÉRIO DA SAÚDE, 2014), a região Nordeste apresenta uma tendência linear de crescimento significativa para notificações de novos casos de AIDS; no ano de 2004 fora registrado 11,0 casos para cada 100 mil habitantes, enquanto que em 2013 foram 16,0 casos para cada 100 mil habitantes. Isto representa um aumento de $45,5 \%$ de casos, o que implica no aumento do número de indivíduos suscetíveis à toxoplasmose, pois sabe-se que há muito tempo que a deficiência do sistema imune é um fator de risco para toxoplasmose, e sua manifestação clínica em indivíduos portadores do HIV é fatal na maioria dos casos. Em pacientes com síndrome da imunodeficiência adquirida (SIDA/AIDS) a toxoplasmose apresenta uma alta taxa de morbi-mortalidade. Portanto, as campanhas devem ser direcionadas não somente a gestantes, mas sim a toda comunidade suscetível à infecção, pois há várias formas de acometimento como a toxoplasmose ocular, cujo tratamento inadequado ou a demora do mesmo pode ocasionar a cegueira.

De acordo com os resultados dispostos na Figura 3 , observa-se que $69 \%(n=719)$ dos indivíduos do sexo feminino apresentam soropositividade em relação a anticorpos IgG contra toxoplasmose, enquanto que $67 \%$ $(\mathrm{n}=37)$ dos indivíduos do sexo masculino apresentam soropositividade para IgG anti-T. gondii. Isto indica que $21 \%$ das mulheres e $33 \%$ dos homens não tiveram contato com o parasita, estando desta forma em risco de contrair a infecção. As taxas observadas no sexo feminino neste estudo não divergem das encontradas por Nascimento et al. (2002) na Bahia, onde 64,92\% da população feminina em estudo apresentaram anticorpos IgG contra toxoplasmose.

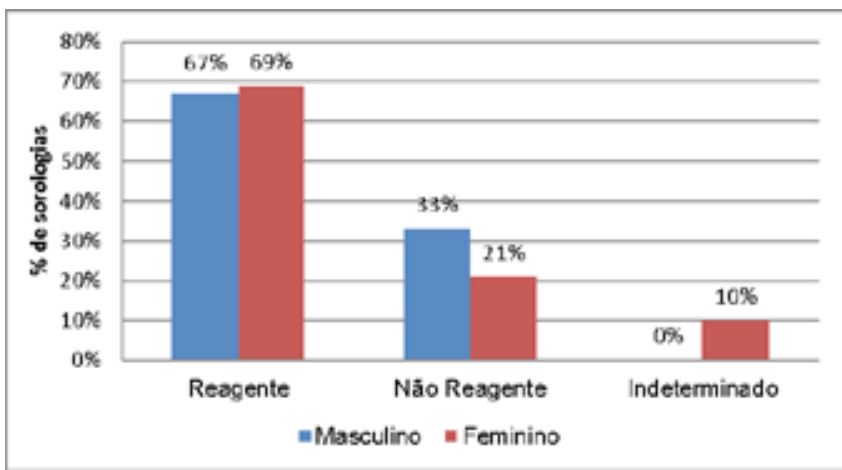

Figura 3. Comparação entre títulos de anticorpos anti-toxoplasma do tipo IgG em relação ao sexo.

Na Figura 4 encontram-se as taxas percentuais na pesquisa de anticorpos IgM. A pesquisa revelou que $6 \%$ da população masculina e $1 \%$ da população feminina apresentaram níveis plasmáticos detectáveis de 
anticorpos IgM anti-T. gondii, ou seja, encontram-se na fase aguda da doença. Os indivíduos do sexo masculino, caso não sejam imunodeficientes, curar-se-ão da infecção. O protozoário, no entanto, viverá ao longo de toda a vida do indivíduo em cistos teciduais.

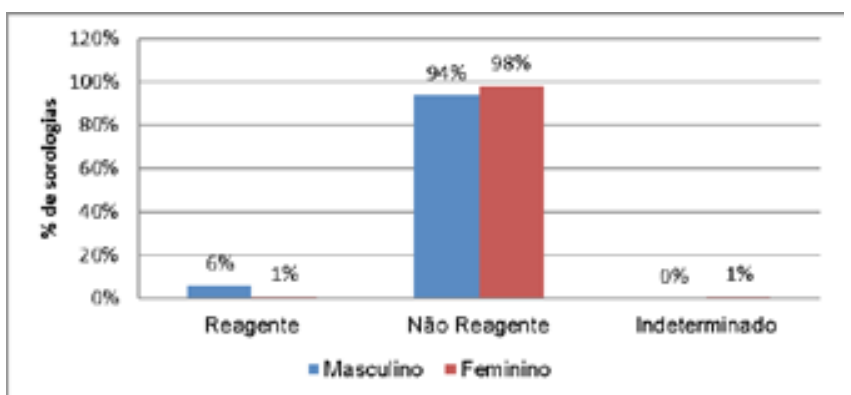

Figura 4. Comparação entre títulos de anticorpos anti-toxoplasma do tipo IgM em relação ao sexo.

As taxas percentuais observadas por Mandai; Lopes; Mitsuka-Breganó (2007), em um estudo sobre a prevalência de anticorpos IgG e IgM anti-T. gondii no município de Londrina, onde $1,7 \%$ dos indivíduos do sexo feminino apresentou anticorpos IgM anti-T. gondii., não diferindo, significativamente, dos encontrados na cidade de Teresina, Piauí. Não há estudos que relatem a prevalência de toxoplasmose em indivíduos do sexo masculino, o que impossibilita a comparação.

Neste estudo, o maior número de indivíduos do sexo feminino se deve ao fato da toxoplasmose possuir maior importância clínica na mulher devido ao período gestacional e ao risco que uma primo-infecção pode acarretar ao feto no período gestacional. Cerca de $61 \%$ dos testes foram solicitados pela Maternidade Dona Evangelina Rosa, e os 39\% restantes são oriundos de outras clínicas.

Os dados relacionados às mulheres desta pesquisa, em sua maioria, eram grávidas assistidas pela Maternidade Dona Evangelina Rosa, a qual solicitou testes para toxoplasmose como parte dos exames prénatais. Não se sabe se os recém-nascidos destas pacientes tiveram alguma sequela ao nascimento, e isto se deve ao fato deste trabalho ser retrospectivo e avaliar apenas os resultados dos testes e não o prontuário do paciente.

Após a análise cuidadosa dos casos obtidos, calculou-se a taxa de prevalência da toxoplasmose na cidade de Teresina, Piauí.

Fora observada uma prevalência de $89,4 \%$ de indivíduos com perfil sorológico apresentando $\operatorname{IgG}$ anti-T. gondii; dessa forma, estima-se que cerca de $90 \%$ da população teresinense já teve contato com o parasito causador da toxoplasmose. Os resultados encontrados nesta pesquisa diferem dos encontrados por Mandai; Lopes; Mitsuka-Breganó (2007) em Londrina, Paraná, onde $56,6 \%$ da população encontram-se infectados pelo protozoário Toxoplasma gondii; assemelham-se ainda aos resultados obtidos por Bittencourt et al. (2012a), em um estudo realizado na região do Paraná onde 59,8 a $60,6 \%$ da população possui anticorpos IgG anti-T. gondii. A prevalência de toxoplasmose na população da cidade de Teresina está acima da encontrada em outras regiões do país, porém, assemelha-se à encontrada por Nascimento et al. (2002), na Bahia, onde 64,58\% da população já foram infectados. Segundo Dubey et al. (2012), no Brasil, 50\% das crianças e $80 \%$ das mulheres têm anticorpos para esse protozoário. Em um estudo feito por Figueiró-Filho et al. (2005), no Estado do Mato Grosso do Sul, fora encontrada uma soroprevalência de 91,6\% assemelhando-se à soroprevalência encontrada na cidade de Teresina, Piauí.

Quanto à prevalência de anticorpos IgM anti-T. gondii, observou-se que 4,3\% da população apresentou sorologia positiva para anticorpos característicos da fase aguda da doença, o que está muito acima do encontrado nas demais regiões brasileiras. No Paraná, Bittencourt et al. (2012b) demonstraram em seus estudos uma taxa de $1,1 \%$ de anticorpos IgM.

Fica evidente que muito estudo adicional será necessário antes da completa compreensão da soroprevalência da toxoplasmose na cidade de Teresina, espera-se que este estudo estimule futuras investigações nessa área.

\section{CONCLUSÃO}

De acordo com o referido estudo concluise que a maioria dos dados obtidos correspondeu a indivíduos do sexo feminino atendidas pela Maternidade Dona Evangelina Rosa, em vista da preocupação em se diagnosticar a toxoplasmose em gestantes e identificar indivíduos cujos sorotipos são negativos. Há negligência quanto à busca de anticorpos anti-Toxoplasma em 
indivíduos do sexo masculino. A prevalência de anticorpos IgG anti-T. gondii, na cidade Teresina, é de 89,4\%, e de anticorpos IgM anti-T. gondii é de 4,3\%, fato este que está em total acordo com o encontrado na literatura científica. Diante do exposto, percebe-se a importância da caracterização epidemiológica da toxoplasmose não somente na cidade de Teresina, mas de todo o Estado do Piauí.

\section{REFERÊNCIAS}

AMENDOEIRA, M. R. R; CAMILLO-COURA, L. F. A brief review on toxoplasmosis in pregnancy. Scientia Medica, v. 20, n. 1, p. 113-119, 2010.

BECK, S. T.; KONOPKA, C. K.; DA SILVA, A. K.; DIEHL, F. P. Importância do rastreamento sorológico da toxoplasmose em gestantes atendidas em ambulatório de pré-natal de alto risco. Rev Saúde, v. 36, n. 1, p. 29-36, 2010.

BITTENCOURT, L. H. F. de B.; LOPES-MORI, F. M. R.; MITSUKA-BREGANÓ, R.; VALENTIM-ZABOTT, M.; FREIRE, R. L.; PINTO, S. B.; NAVARRO, I. T. Seroepidemiology of toxoplasmosis in pregnant women since the implementation of the Surveillance Program of Toxoplasmosis Acquired in Pregnancy and Congenital in the western region of Paraná, Brazil. Rev Bras Ginecol Obstet., v. 34, n. 2, p. 63-68, 2012.

BRANCO, B. H. M.; ARAÚJO, S. M.; FALAVIGNAGUILHERME, A. L. Prevenção primária da toxoplasmose: conhecimento e atitudes de profissionais de saúde e gestantes do serviço público de Maringá, estado do Paraná. Scientia Medica, v. 22, n. 4, p. 185-190, 2012.

CASTILHO-PELLOSO, M. P.; FALAVIGNA-GUILHERME, A. L.; FALAVIGNA, D. L. M.; DE ARAÚJO, S. M. Monitoring of pregnant women with toxoplasmosis in Public Health Services. Rev Soc Bras Med Trop., v. 38, n. 6, p. 532-533, 2005.

COSTA, M. L.; FREITAS, A. de O.; RODRIGUES, R. M.; DE MELO, F. C. S. A.; SANTA-RITA, R. de M. Levantamento do perfil epidemiológico da Toxoplasmose na Cidade de Jataí-GO. [s.l.]: Universidade Federal de Goiás, [2013].

COSTA, R. C. de B. Aspectos epidemiológicos e importância da toxoplasmose na sanidade animal e na saúde pública. 2013. 36f. Seminário (Seminários aplicados do Programa de Pós-graduação em Ciência Animal da Escola de Veterinária e Zootecnia da Universidade Federal de Goiás) - Universidade Federal de Goiás, 2013.

DUBEY, J. P.; LAGO, E. G.; GENNARI, S. M.; SU, C.; JONES, J. L. Toxoplasmosis in humans and animals in Brazil: high prevalence, high burden of disease, and epidemiology. Parasitology, v. 139, n. 11, p. 1375-1424, 2012.

EDUARDO, M. B. de P.; KATSUYA, E. M.; RAMOS, S. R. T. S.; PAVANELLO, E. I.; PAIVA, O. R.; BRITO, S. do N.; MADALOSSO, G. Toxoplasmosis outbreak investigation associated with raw meat dish named ("steak tartar"), in the cities of São Paulo and Guarujá, SP: November 2006. BEPA, Bol. Epidemiol. Paul. (Online), v. 4, n. 41, p. 2-7, 2007.

FERREIRA, A. M. Caracterização molecular de Cepas de Toxoplasma gondii Isoladas no Brasil. 2004. 201f. Tese. (Doutorado em Parasitologia) - Instituto de Ciências Biológicas, Universidade Federal de Minas Gerais, 2004.

FERREIRA, I. M. R. Genotipagem de cepas polimórficas de Toxoplasma gondii provenientes de pacientes com toxoplasmose. Tese. (Doutorado em Ciências) Coordenadoria de Controle de Doenças da Secretaria de Estado da Saúde de São Paulo, São Paulo, 2012.

FIGUEIRÓ-FILHO, E. A.; SENEFONTE, F. R. de A.; LOPES, A. H. A.; DE MORAIS, O. O.; SOUZA JÚNIOR, V. G.; MAIA, T. L.; DUARTE, G. Acute toxoplasmosis: study of the frequency, vertical transmission rate and the relationship between maternal-fetal diagnostic tests during pregnancy in a Central-Western state of Brazil. Rev Bras Ginecol Obstet., v. 27, n. 8, p. 442-449, 2005.

MANDAI, O. N.; LOPES, F. M. R.; MITSUKA-BREGANÓ, R. Prevalência de anticorpos igG e igM anti-Toxoplasma gondii em gestantes atendidas nas unidades básicas de saúde do município de Londrina - Paraná, no período de 
2003 e 2004. Rev Bras Anal Clin., v. 39, n. 4, p. 247-249. 2007.

MEDEIROS, A. D. Ocorrência da infeccção por Toxoplasma gondii e avaliação da imunização em caprinos do sertão do Cabugi, Rio Grande do Norte. 2010. Dissertação. (Mestrado) - Universidade Federal do Rio Grande do Norte (UFRN), Rio Grande do Norte, 2010.

NADIR JÚNIOR, G. de; DE NADIR, K. F.; COLENCI, R.; DOS SANTOS, E. L. B. Toxoplasmose: aspectos de saúde pública e importância ao agronegócio. Tékhne e Lógos, v. 3, n. 1, 2012.

NASCIMENTO, I.; CARVALHO, S.; CARDOZO, N.; ASFORA, S.; CAMPOS, A.; MENEZES, S.; SIMÕES, J.; SCHAER, R. E.; MEYER, R. Study of the prevalence of antibodies antiToxoplasma gondii in pregnant women in Bahia. Rev Ciênc Méd Boil., v. 1, n. 1, p. 12-15, 2002.

VAZ, R. S.; RAULI, P.; MELLO, R. G.; CARDOSO, M. A. Toxoplasmose Congênita: uma doença negligenciada? atual política de saúde pública brasileira. Field Actions Scie Reports, n. 3 especial, 2011. Disponível em: < http:// factsreports.revues.org/1107>. Acesso em: 2014.

Recebido em: 30 de setembro de 2015 Aceito em: 11 de novembro de 2015 